\title{
EXTENDING 3D QUALITY MODELLING FOR EARTHQUAKE-DAMAGED STONE MASONRY WALL: COMBINED DIGITAL MODELS FOR BUILDING ARCHAEOLOGY
}

\author{
C. Stanga ${ }^{1, *}$, R. Brumana ${ }^{2}$, M. Previtali ${ }^{2}$, A. G. Landi ${ }^{1}$, F. Banfi ${ }^{2}$ \\ ${ }^{1}$ Politecnico di Milano, Dept. of Architecture and Urban Studies (DAStU), via Bonardi 9, Milan, 20133 Italy - (chiara.stanga, \\ angelogiuseppe.landi)@polimi.it \\ ${ }^{2}$ Politecnico di Milano, Dept. of Architecture, Built Environment and Construction Engineering (ABC), via Ponzio 31, Milan, 20133 \\ Italy - (raffaella.brumana, mattia.previtali, fabrizio.banfi)@polimi.it
}

KEY WORDS: Heritage Building Information Model (HBIM), Scan-to-BIM, Photogrammetry, Information sharing, Building Archaeology, Virtual Reality

\begin{abstract}
:
The paper proposes an approach for defining a generative modelling process of complex objects and their sharing. The case study is the Stronghold of Arquata del Tronto, a monument of extraordinary historical, cultural and landscape value, damaged by the earthquake in 2016. The first step has been data acquisition on a geometrical level, through laser scanner and UAV photogrammetry, and on a historical level, through archival research to understand construction phases and transformations. The Stronghold was probably built between the 11 and the 12th century on a hill to control the territory. It underwent several transformations and neglection phases over the centuries. The second phase has been the generative modelling following the scan-to-BIM approach. The three-dimensional model is intended to support the design phases, from preliminary analysis to the construction site.

For this reason, the Stronghold has been modelled with different Grade of Generation (GOG). The study of the eastern curtain wall, where the signs suffered by the structure due to the earthquake are most evident, was deepened through a Building Archaeology preliminary analysis. The third phase aimed at orienting the HBIM towards three digital information-sharing solutions such as Common Data Environment (CDE), and Virtual Reality (VR) to enhance the cultural and historical values, supporting the reopening of the Stronghold as a venue for conferences and exhibitions.
\end{abstract}

\section{INTRODUCTION}

The growing use of information models requires the definition of criteria for their sharing. Together with sharing the model, it is necessary to give information on its level of accuracy or the purpose for which it was generated, together with the name of its owner. Informative models could be shared in the form of object libraries within the Common Data Environment. Nevertheless, object libraries are not oriented to the Architectural Heritage and they do not cope with the complexity and uniqueness of each historical building. Furthermore, since it is possible to add parameters and information to each component, the HBIM becomes the space where metadata is included and shared (Quattrini et al., 2017).

In April 2019, 27 Member States of the European Union had committed to the importance of digital technologies by signing the Declaration of Cooperation on advancing the digitisation of cultural heritage on Digital Day. By doing so, they endorsed the call for common standards, methodologies and guidelines for the holistic 3D documentation of European Cultural Heritage.

In April 2020, the European Commission launched a call for tenders to carry out for the first time a Study on quality in 3D digitisation of tangible cultural heritage (VIGIE 2020/654). The purpose of the call is to map parameters, formats, standards, benchmarks, methodologies and guidelines, relating to the $3 \mathrm{D}$ digitisation of tangible cultural heritage. Addressing the different potential purposes or uses, by type of tangible cultural heritage, and the degree of complexity of tangible cultural heritage, the paper summarised part of the on-course study on quality in $3 \mathrm{D}$ digitisation, to which the POLIMI research group is participating as Third Party proposing specifications to acquire, generate and share 3D models addressed to support XR/AR/VR and HBIMs, guaranteeing an 'informed' choice by the different targeted users, and guaranteeing the correct re-use within cloud platforms. Furthermore, the paper intends to study novel scan-to-BIM parameters to generate and share reliable $3 \mathrm{D}$ models in the specific domain of the 'Building Archeology'.

One of the case studies is the Rocca (Stronghold) di Arquata del Tronto (Ascoli Piceno, Italy), struck by the earthquake in 2016. The integrated approach between advanced 3D survey techniques, digital information models (HBIM), and virtual reality, has made it possible to define digital data flows to communicate a large amount of content, from material and decay analyses to the identification of historical phases. Thanks to the integrated use of laser scanners (terrestrial and mobile), total station and photogrammetry (terrestrial and UAV) it was possible to define an environment characterised by many point clouds able to describe through points the internal and external geometry of the Stronghold. Although the main structures were secured, thanks to a post-processing phase, it was possible to intercept and distinguish the wall partitions from the structures used to support the damaged elements. Once the heritage of the Stronghold was deepened on a historical and cultural level, it was possible to start the digitisation process (scan-to-BIM). The generation of the HBIM envisaged the use of different Grades of Generation (GOG) and Accuracy (GOA) with the primary objective of returning the digital representation of the building depending on the purposes of the research. Thanks to the integrated use of nonuniform rational basis-splines (NURBS) modelling and scan-toBIM requirements, it was possible to achieve different levels of complex geometry, attributing a reference value to each recreated object capable of communicating its reliability from a morphological point of view (Brumana et al., 2021). 


\section{RESEARCH OBJECTIVES}

The article describes an approach for defining a generative modelling process of complex objects that provides different degrees of knowledge at a geometric and historical level. The case study is the Stronghold of Arquata del Tronto, a monument of extraordinary historical, cultural and landscape value, damaged by L'Aquila earthquake in 2016. The three-dimensional model is intended to support the design phases, from preliminary analysis to the construction site. For this reason, the Stronghold has been modelled with different Grade of Generation (GOG).

The article proposes the modelling of the eastern curtain wall, where the signs suffered by the structure due to the earthquake are most evident.

The HBIM of the Stronghold is oriented towards three digital information-sharing solutions such as Common Data Environment (CDE), and Virtual Reality (VR) to enhance the cultural and historical values, supporting the reopening of the Stronghold as a venue for conferences and exhibitions (Petrucci et al. 2020)

In particular, the main research objectives are:

- $\quad$ CDE allows for the more effective carrying out of a renovation, maintenance and new construction activities with results that respect the quality, times and costs provided in the preliminary design plan,

- the information generated and managed clearly and directly can be subsequently aggregated, distributed, updated and modified, made available according to the objectives and purposes of the HBIM-based project,

- explore and expand the latest VR technologies for different types of users, devices and applications in the digital cultural heritage domain.

\section{HISTORICAL BACKGROUND}

Unlike the other provinces in the Marche, Ascoli Piceno has many villages that result from more or less substantial transformations of a castle, whose defensive structures are often still preserved. What should be noted is the special relationship that these structures establish with the territory, which defines an exceptional environmental value, whereby the places become poles of significant architectural, landscape and cultural values (Campagnoli 1985, p. 40).

Arquata del Tronto has always been a border area, which allowed the fortification of the hill between the 11th and 12th centuries. The Stronghold stands on a cliff in a dominant position for the town of Arquata del Tronto and the surrounding area, a strategic location to control the ancient Roman Via Salaria and the access to the Galluccio pass, which allowed to reach Montegallo and then Norcia (Galié, Vecchioni 2006, p. 80).

The Stronghold (Figure 4) consists of a square donjon (about $7 \mathrm{~m}$ per side, H. $24 \mathrm{~m}$ ), which the literature dates to the 14th century. It is probably one of the first elements of the system, then curtain walls were added. The two bastions were built later: the polygonal one in the southeast corner (it occupies an area of about $8 \mathrm{x} 8 \mathrm{~m}$ ) and the circular one (a three-centered arch with a buttress, $12 \mathrm{~m}$ distance between the arch) in the southwest corner, whose traces are still visible. A curtain wall joins the donjon and the polygonal bastion on the eastside with a "broken" line profile faced by a scarp. Finally, the western curtain wall joins the donjon to the circular bastion on the south, and perhaps it continues towards the northern scarp, as some of the donjon quoins would suggest.

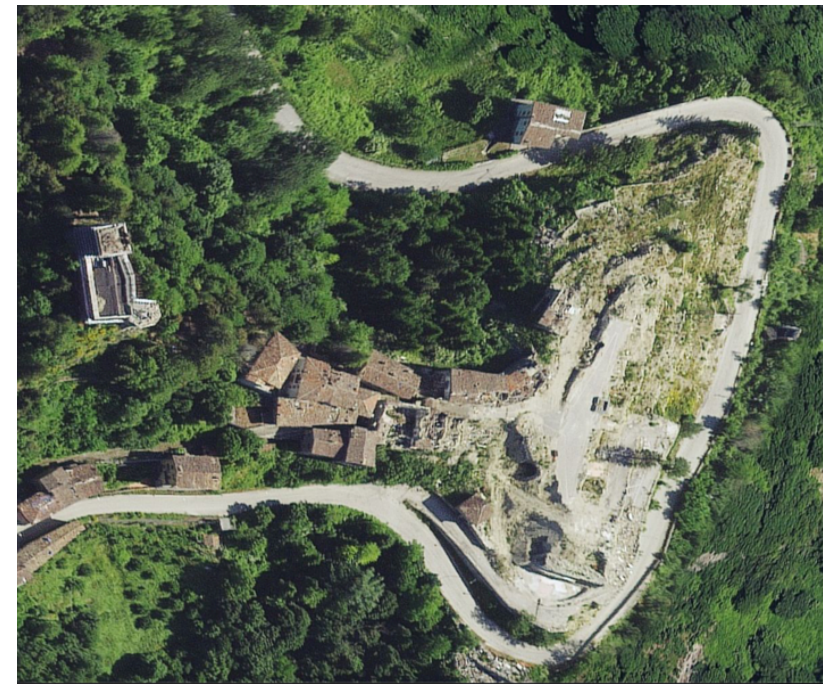

Figure 1. The stronghold standing on the hill surrounded by Borgo di Arquata (Google Maps)

The Stronghold is the result of the stratification carried out over the centuries: it has undergone numerous changes, even for adapting the structure to the war technological needs. For this reason, an abstraction process of virtually subtracting the past and recent restorations would help to understand the chronological sequences, thus the different construction techniques. Starting from what has been modified since the 20th century, when the Stronghold has undergone different maintenance works and restorations, following periods of abandonment and earthquake events, going back over the centuries.

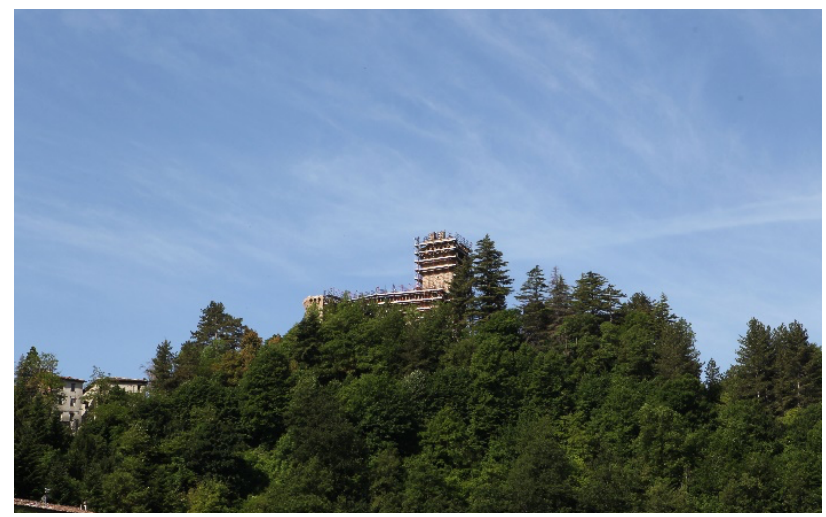

Figure 2. The Stronghold

The historical archival research has thus focused on the documents testifying transformations and maintenance works between the transfer from the State Property to the Municipality of Arquata (January 1890) and the 1990s restoration.

Following the Aquila earthquake in 1703, maintenance was required, but after various events, during which the Ascoli government and the city of Norcia alternated their control, the Stronghold was abandoned at least around the end of the 18th century.

At the beginning of the 20th century, a gradual restoration strategy was developed following an instance of the Commissione Conservatrice dei Monumenti which recognise the Stronghold as a significant testimony of the Italian Medieval commune. It involves a first series of interventions under the supervision of architect Dante Viviani. The first works were 
realised between 1904 and 1906 and mainly concerned the donjon and the polygonal bastion.

In 1909 and 1911, the second works focused on the overhanging battlements of the polygonal bastion and few portions of the curtain walls. The photograph preserved in the Central State Archive of Rome, which portrays the abandoned Stronghold, can be dated to the early 20th century (Figure 3 ).

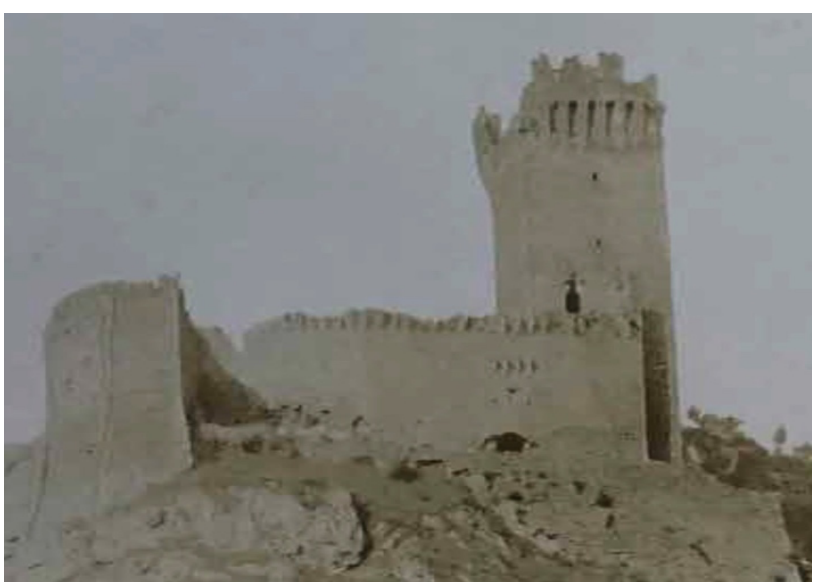

Figure 3. The Stronghold, beginning of the XX century (Archivio Centrale dello Stato, Rome)

To be noted, the eastern curtain wall: the battlements were partially ruined, the door was wider than today, and the wall towards the polygonal bastion was partially collapsed. Other works were carried out in 1922 on the eastern and western curtain walls and again between 1946, following the earthquake of 1943. In the 1960s, some works were realised on the donjon, and the last intervention in the 1990s was aimed at the adaptation of the Stronghold to a conference venue (Facchi et al. 2020).

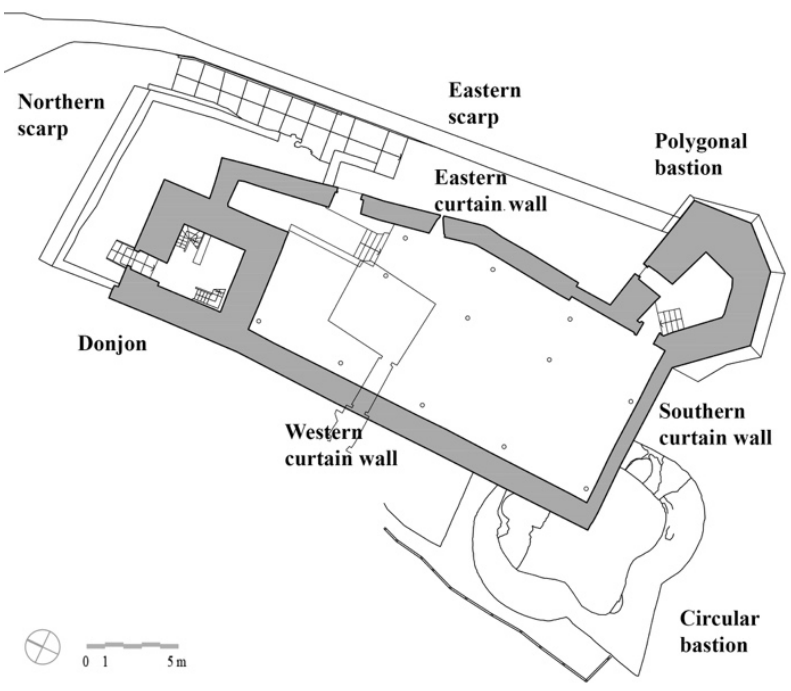

Figure 4. Plan of the Stronghold

\section{3D SURVEY}

The geometrical survey of the stronghold was carried out in the survey campaign of May 2019 (Figure 5). Due to the complexity of the surveying conditions, determined by the presence of temporary safety scaffolding, a geodetic network was established to allow a strong reference for the alignment of the scans acquired.

In particular, the geodetic network established is composed by 9 benchmarks inside the stronghold and in the surrounding areas. The benchmarks inside the stronghold were located at both at ground and at the roof level while in the surrounding are benchmarks were located to form a loop around the stronghold. The materialised geodetic network was measured with Leica TPS1200 total station and multiple intersection among the benchmarks were carried out to increase reliability of the network. The network was compensated by least-squares adjustment providing an average precision of less than $1.0 \mathrm{~mm}$ on the benchmarks.
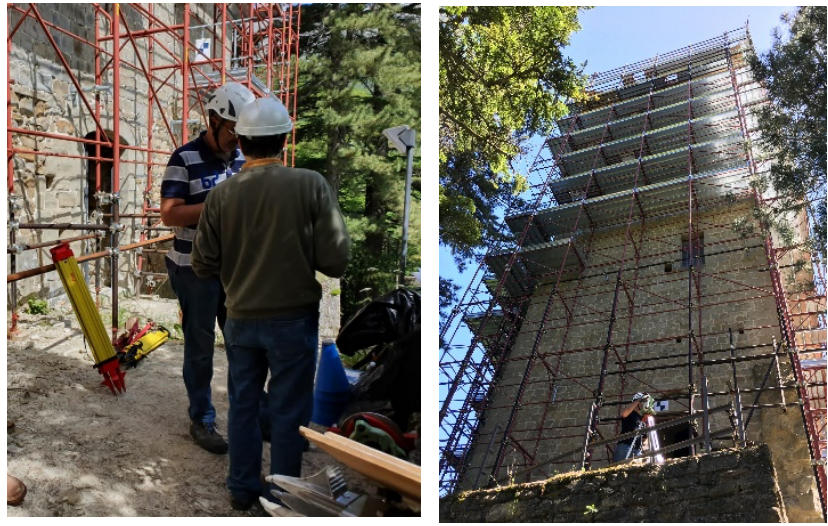

Figure 5. Survey campaign (May 2019)

The survey the current state of stronghold a static laser scanning survey war carried out. The registration of the scans was performed by using a target-based approach in addition to targets used for scan-to-scan registration 54 targets were measured in the same local reference system defined by the local geodetic network (average precision of targets measured with total station $\pm 2.0 \mathrm{~mm}$ ). To complete the survey of the stronghold 73 scans were acquired by using a Faro Focus 3D and registration presents an average precision of the targets of $\pm 4.7 \mathrm{~mm}$ (Figure 6). Identifying stable points on the scaffolding for performing the scan was partially solved by using a specific mounting to be used to fix the laser scanner in correspondence of the stable anchoring of the scaffolding.

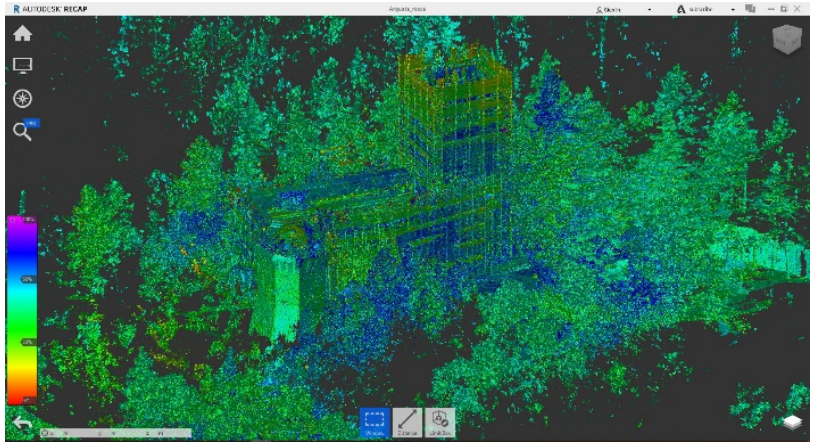

Figure 6. Point cloud (RecapPro) 
Due to the presence of the scaffolding, it was not possible to perform a complete photogrammetric survey (both terrestrial and UAV) of the external walls of the stronghold. However, some documentation images were taken by the municipality of Arquata with a drone right after the earthquake and before the installation of the scaffolding.
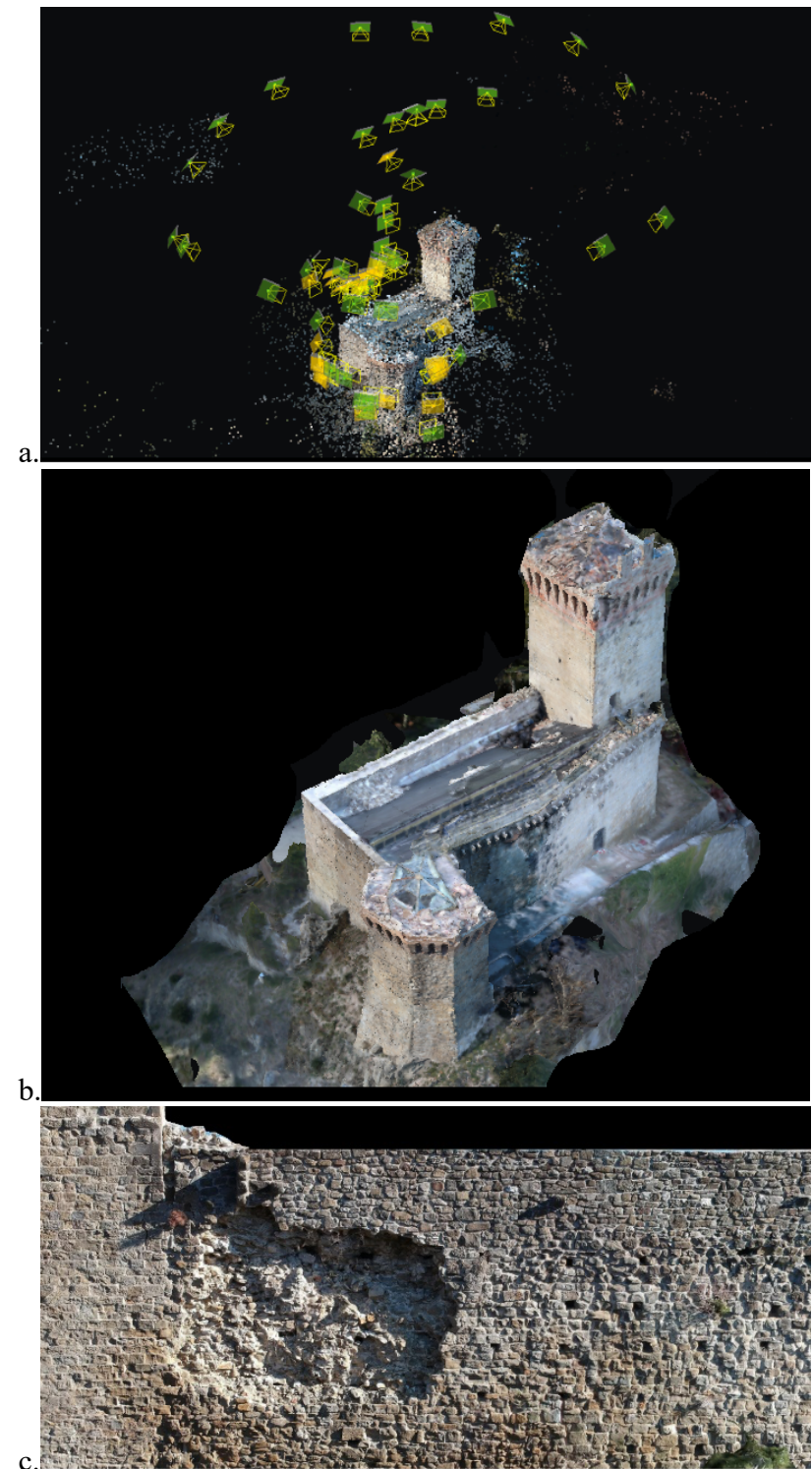

Figure 7. Photogrammetric reconstruction of the stronghold: a) image alignment; b) final mesh and c) detail of the orthophoto of the west wall

The main issue with these data was the fact that they were not acquired for photogrammetric purposes and some of them are characterised by poor geometry (short baseline and reduced overlap) and strong shadows. Unless those limitations the dataset was processed and georeferenced by using as GCP some points acquired with the total station. Final accuracy on GCP is $\pm 2.0 \mathrm{~cm}$ (Figure $7 a-b$ ). Starting from this survey orthophotos were derived for the main elevations of the building (Figure $7 \mathrm{c}$ ).

\section{3D QUALITY MODEL SPECIFICATION FOR BUILDING ARCHAEOLOGY: THE CASE OF THE EASTERN WALL}

The Stronghold HBIM was modelled for a scale 1:50 (GOA50, Polyginal bastion) and GOA20 (Donjon), till GOA10 for the eastern curtain wall, while the northern, western and southern curtain walls were generated with GOA100. Table 1 shows the model scales and GOA for each element.

Since the Stronghold walls were severed damaged by the earthquake (out-of-plumbs, cracks, ...) it was decided to obtain a detailed HBIM model, starting from the eastern curtain wall, following the Building Archaeology preliminary analysis (Brogiolo and Cagnana, 2012; Doglioni, 1997) (Figure 8). The facade was modelled following GOA10 to represent, where it was possible, 3D objects (stones, mortar, plaster, ...) capable of appropriately interpreting and sharing the quantities relating to the different materials and construction techniques. The granularisation of the model could follow the needs of a hypothetical restoration intervention, which requires the elements to be differentiated according to material and decay analysis or bill of quantities. Moreover, HBIM Building Archaeology is a critical tool to interpret the building component constructive and chronological relationship, and "structural discontinuities".

\begin{tabular}{|c|c|c|c|}
\hline Building component & GOA & Scale & Tolerance \\
\hline $\begin{array}{l}\text { Northern, Western and } \\
\text { Southern curtain walls }\end{array}$ & 100 & $1: 100$ & $40-60 \mathrm{~mm}$ \\
\hline Polygonal Bastion & 50 & $1: 50$ & $20-30 \mathrm{~mm}$ \\
\hline Donjon & 20 & $1: 20$ & $8-12 \mathrm{~mm}$ \\
\hline $\begin{array}{l}\text { Eastern curtain wall, ashlar } \\
\text { stone masonry, 3D volume } \\
\text { stratigraphy following the } \\
\text { Building } \\
\text { analysis }\end{array}$ & 10 & $1: 10$ & $4-6 \mathrm{~mm}$ \\
\hline
\end{tabular}

Table 1. Model scales and GOA for each building component of the Stronghold

As mentioned before, the Stronghold is the result of stratifications that have occurred over the centuries. The analysis of the eastern curtain wall offers some considerations on the study of the construction techniques, the consolidation interventions, the repairs due to the damages of past and recent earthquakes. The analysis is focused on the different stone-wall textures without defining specific intentionality or constructive sequences between them. It is a preliminary analysis that can be later deepened with more in-depth studies. Further study would then consider the wall repointed joints, which do not allow us to thoroughly understand the relationship among the different areas. The eastern curtain wall is characterised by a base consisting of larger-sized stones having the same height within each course, especially towards the northern side (T13 - these courses correspond to quoins of larger dimensions than the upper part). The upper part has a less regular texture (squared rubble), and the stones vary in shape and size (T3).

The $\mathrm{T} 2$ has a more regular texture considering courses and shapesize stones (coursed ashlar). Four corbels consist of three pieces each are placed in this 'unit', above the door. Under the corbels, a trilithic system, perhaps an opening or a niche. The relationship between T2 and T3 remains to be understood: how is it possible to explain the presence of a regular wall texture on the top of an irregular one? Perhaps the T3 was made following a more orderly T2 collapse? However, it seems that both units are external facing of the rubble masonry, whom inner core is visible in the parts of the masonry damaged by the earthquake (T1). 
Scan-to-BIM
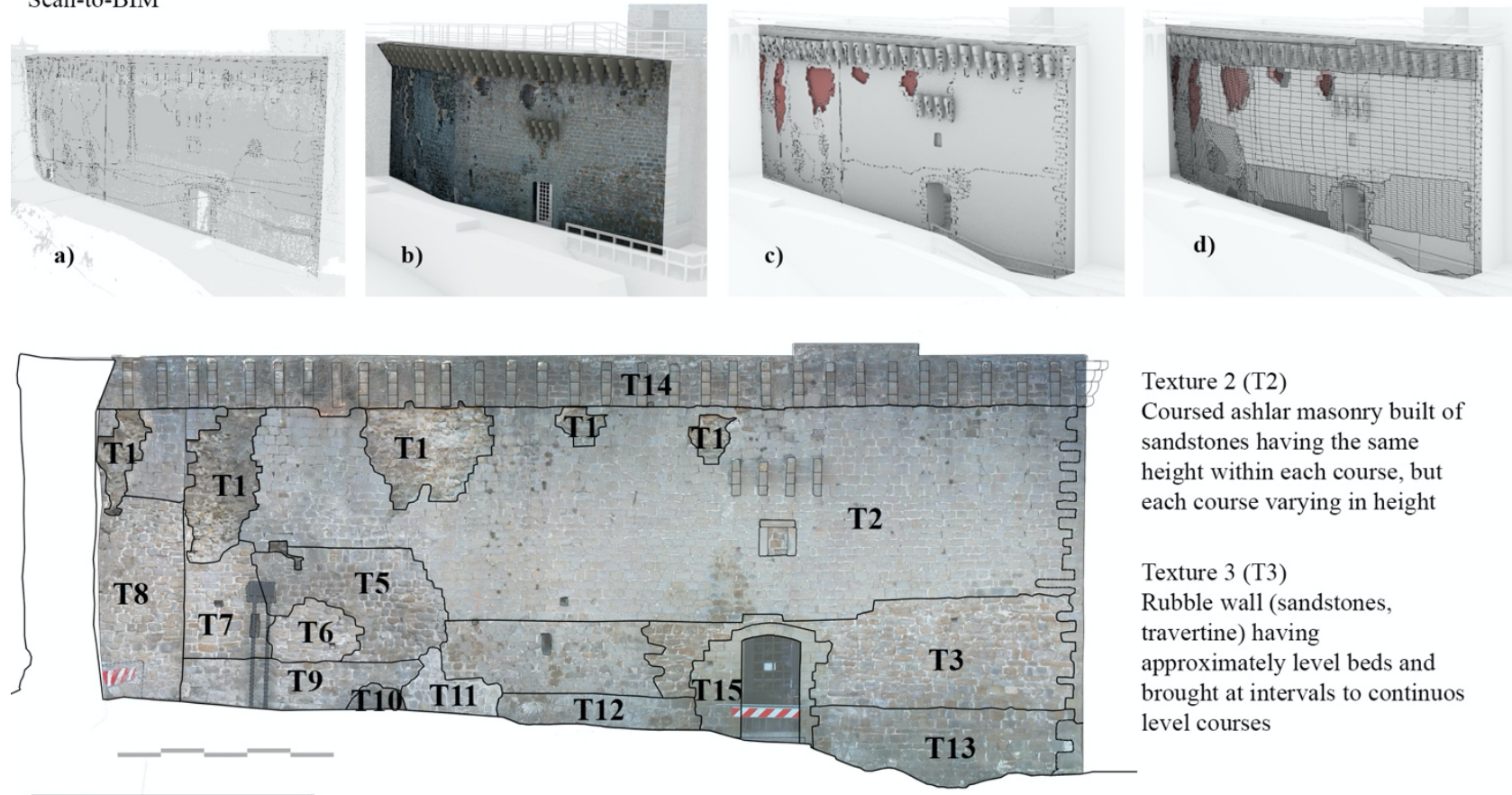

Texture 2 (T2)

Coursed ashlar masonry built of sandstones having the same height within each course, but each course varying in height

Texture 3 (T3)

Rubble wall (sandstones,

travertine) having

approximately level beds and

brought at intervals to continuos

level courses

Figure 8. HBIM for Building Archaeology: stratigraphic units (texture) extracted from the NURBS: thanks to GOG9 and GOG10 it has been possible to directly identify the analysis in the 3D environment using NURBS algorithms: (a) point clouds; (b) textured model, (c) NURBS surfaces; (d) extraction of 3D primitives

The corbels (as a part of the battlement) and the wall adjacent to the polygonal bastion are instead the most remodelled over time. Figure 3 represents the state of the eastern curtain wall at the beginning of the 20th century. The wall adjacent to the polygonal bastion and the corbels are partially ruined, while the door is wider than today, as evidenced by the T15.

The materials used for the masonry of the Stronghold are squared ashlars of sandstone and travertine. As can also be seen through the analysis of the eastern curtain wall, the sandstone ashlars have different colors and textures, as they probably come from different quarries. Travertine blocks are mainly present on the side of the polygonal bastion (T6, T7, T8), while T10 refers to the stone spur on which the Stronghold was built, which is even visible inside the building.

The units were imported into the HBIM environment to set thickness and 3D relationships among them. Furthermore, this step is essential to link properties (type of stone, state of conservation, material decay, ...) to individual objects and make the study and conservation procedures easier (Figure 9).

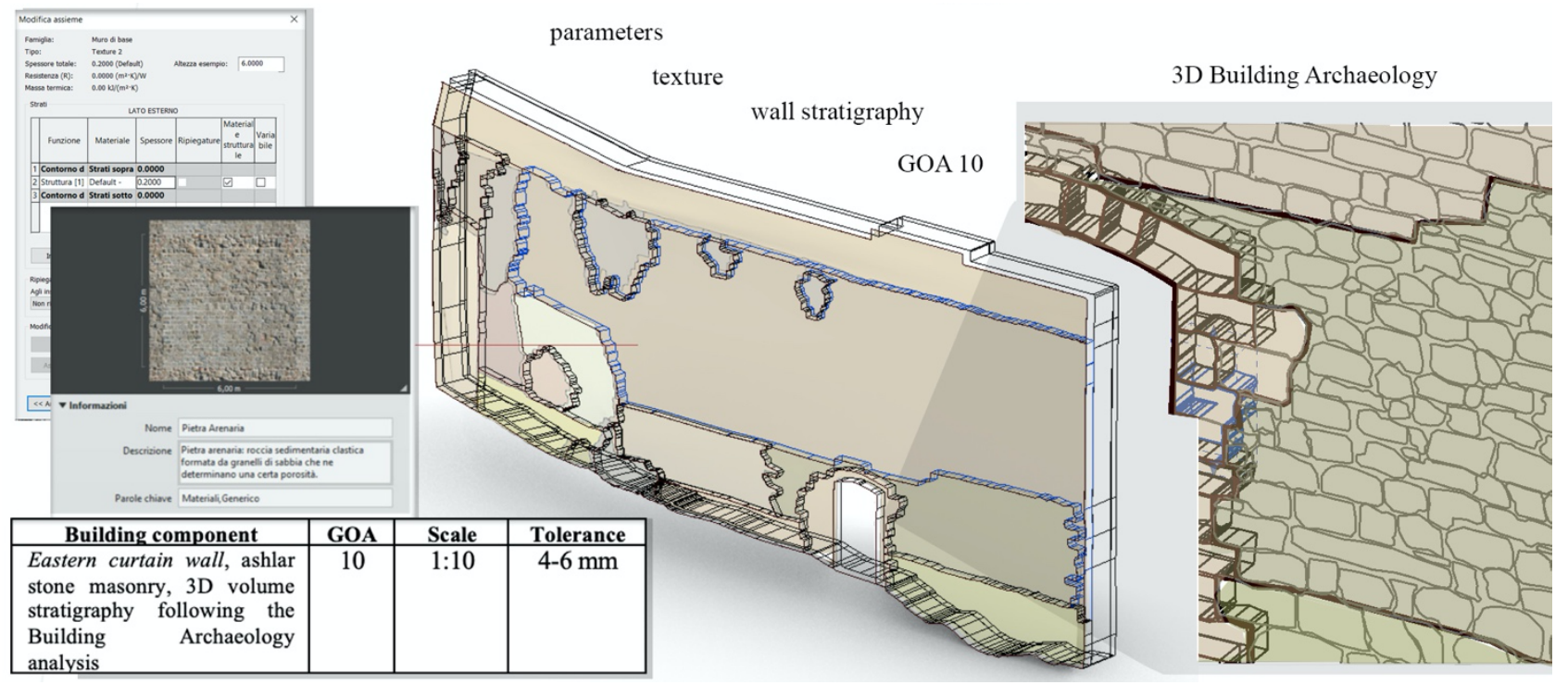

Figure 9. HBIM for Building Archaeology: wall stratigraphy and parameters 


\section{HBIM PROJECT DEVELOPMENT: FROM SCAN- TO-BIM TO MANAGEMENT COMPLEXITY}

In recent years, HBIM projects have demonstrated how the digitisation process of complex buildings allows for improved management of the building life cycle, from the first phase of the survey to restoration, preservation and scheduled maintenance. Thanks to a scan-to-BIM process applied to the Stronghold of Arquata del Tronto, it was possible to expand the information value of the various HBIM objects, intercepting and representing the geometric complexities in the best possible way. Consequently, the process was based on the application of different degrees of generation (GOG), which, thanks to the fusion of NURBS modeling with the BIM process, it was possible to transform a large amount of point clouds into HBIM objects capable of receiving different types of information useful for the restoration process (Banfi 2020). As demonstrated in the previous paragraph, the identification of material information, masonry stratigraphy, historical phases, physical and mechanical characteristics has allowed the transmission of information to different disciplines within the process, exponentially increasing the usefulness of HBIM models for different disciplines such as structural analysis, restoration, construction site, plant engineering.

For the digitisation process of the Stronghold, 9 steps have been identified that can explain the geometric-information complexity of a building damaged by the earthquake (Chiabrando et al. 2017) (Figure 10):

- cleaning and orientation of point clouds from laser scanning through interoperable exchange formats with both NURBS modeller and BIM platform,

- cleaning and orientation of point clouds and orthophotos from digital photograms (aerial and terrestrial) through interoperable exchange formats both with NURBS modeller and BIM platform,

- application of generation degrees, from 1 to 10 to intercept geometric primitives, creation of NURBS entities and subsequent transformation into HBIM objects,

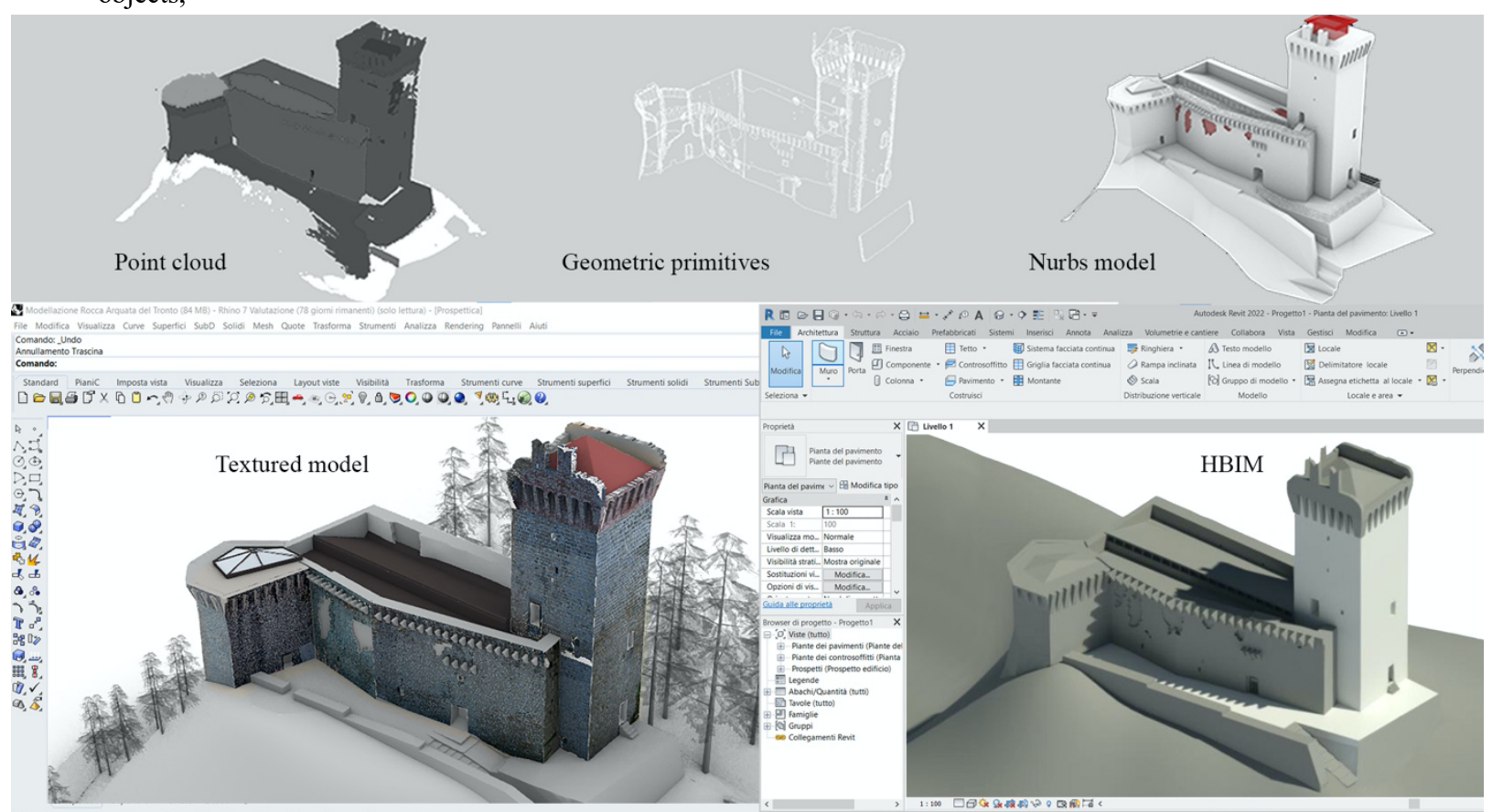

- verification of the reliability of each HBIM object created thanks to an automatic verification system (AVS) capable of determining the standard deviation between the point cloud and the model,

- development of HBIM parameters for each object to declare information relating to the digitisation process such as the grade of accuracy, the data sources used (primary and secondary data sources),

- $\quad$ association of information of different nature to expand the information value of each individual digitised HBIM object,

- automatic extraction of geometric values such as area, the volume of walls, the volume of rooms in schedules and databases,

- database implementation with the aim of associating extracting and sharing information through a shared BIM cloud logic,

- $\quad$ sharing and orientation of HBIM objects for different types of use, including VR.

For this last phase, the sharing of information models through the implementation of an HBIM platform made it possible to express specific values to different types of users, from BIM experts to professionals not oriented to the management of BIM models. This sharing mode based on open and proprietary formats such as IFC, FBX, DXF, DWG, GBXLM, etc., has also made it possible to reach different devices, from $\mathrm{PC}$ workstations to mobile devices and tablets. On the other hand, the process described so far did not allow to go beyond the sharing of models between experts in the construction sector and to reach wider forms of sharing. Consequently, the urgency to share tangible and intangible values enucleated in the models, has led the authors to investigate the most up-to-date forms of interaction in the field of virtual and augmented reality (VR) intending to reach not only professionals but also users not involved in the restoration process such as virtual tourists, the local community of Arquata del Tronto, students and scholars interested in both the safeguarding of the built heritage and its historical and cultural background (Jang et al. 2021).

Figure 10. The HBIM Model of the of the Stronghold 


\section{HBIM MODEL INTEROPERABILITY FOR VR AND COMMON DATA ENVIROMENT (CDE)}

The urgency of transmitting heterogeneous information for different types of users and disciplines has led the authors to investigate the levels of interoperability of BIM models and the related exchange formats to be able to share it through two types of sharing (cloud and virtual reality).

Consequently, these final phases linked to the digitisation of the case study, required the in-depth analysis of IT development techniques aimed at creating a common data environment (CDE) capable of:

- $\quad$ view detailed data directly in the browser and offers support for over 50 file formats, including Autodesk $\AA$, Solidworks ${ }^{\circledR}$, CATIA ${ }^{\circledR}$, Pro-E ${ }^{\circledR}$, Rhino ${ }^{\circledR}$ and $\mathrm{NX}{ }^{\circledR}$ file formats,

- $\quad$ communicate and obtain feedback in real-time from all those involved in the project,

- transform design files into shared, intelligent workspaces by inserting comments within design files,

- quickly search, filter, and find design information in design models, complex assemblies, data repositories, and project activity feeds,

- $\quad$ projects can be accessed from a smartphone or tablet with the Mobile app for iOS and Android,

- $\quad$ share interchange formats, QR codes and links to HBIM objects oriented to Virtual reality.

The development process consequently provided for the use of many computer resources and knowledge. Through Autodesk Forge, it was possible to access and use the data created via the cloud. The platform's main feature is to include a series of APIs (Application Program Interfaces) and SDKs (Software Development Kits) which, for example, make it possible to view 3D models and related information. Within Forge it was possible to use a Viewer, which allowed the display of 3D and 2D files which also allowed commenting, underlining, and measuring.
The APIs have been combined with existing software to innovate the working method and get more from the data in their possession. In addition, the Model Derivative API, which made it possible to obtain output that can be viewed in the Viewer from over 60 CAD file formats and extract metadata on models and individual objects within the model. Other APIs included concern Design Automation, optimising repetitive design tasks, and Reality Capture, to convert digital images into point clouds or high-resolution textured meshes.

On the other hand, the levels of human-machine interaction were not sufficient to be able to expand the IT value of some types of HBIM objects. To connect reality as much as possible with digital models, a 3D real-time synchronisation mapping process has been developed. This special synchronisation technique between NURBS, HBIM textured 3D objects and XR development platforms such as Unreal Engine and Twinmotion allowed authors to exponentially reduce the creation of a virtualvisual storytelling (VVS) of the research case study.

Twinmotion allowed authors a direct one-click synchronisation of geometry and textures coming from photogrammetry with HBIM hierarchy and organisation were retained while native surfaces and $3 \mathrm{D}$ objects were automatically substituted for Twinmotion objects that react to the environment.

This development allows users to continue to iterate in $3 \mathrm{D}$ application using Datasmith's nondestructive re-import feature, adding new changes to the real-time scene and automating Python scripting.

Figure 11 shows one of the main interactive virtual objects (IVOs) implemented for the VVS. The platform reads the IVOs in the frame, the system recognizes it and activates a new level of communication, enhancing the amount of detailed data in relation to that HBIM model. For the architectural components of the case study, it was possible to deepen and understand more completely the planning of space and the visualization of material and historical analyses and reconstruction design hypotheses using mobile devices and accurate description.

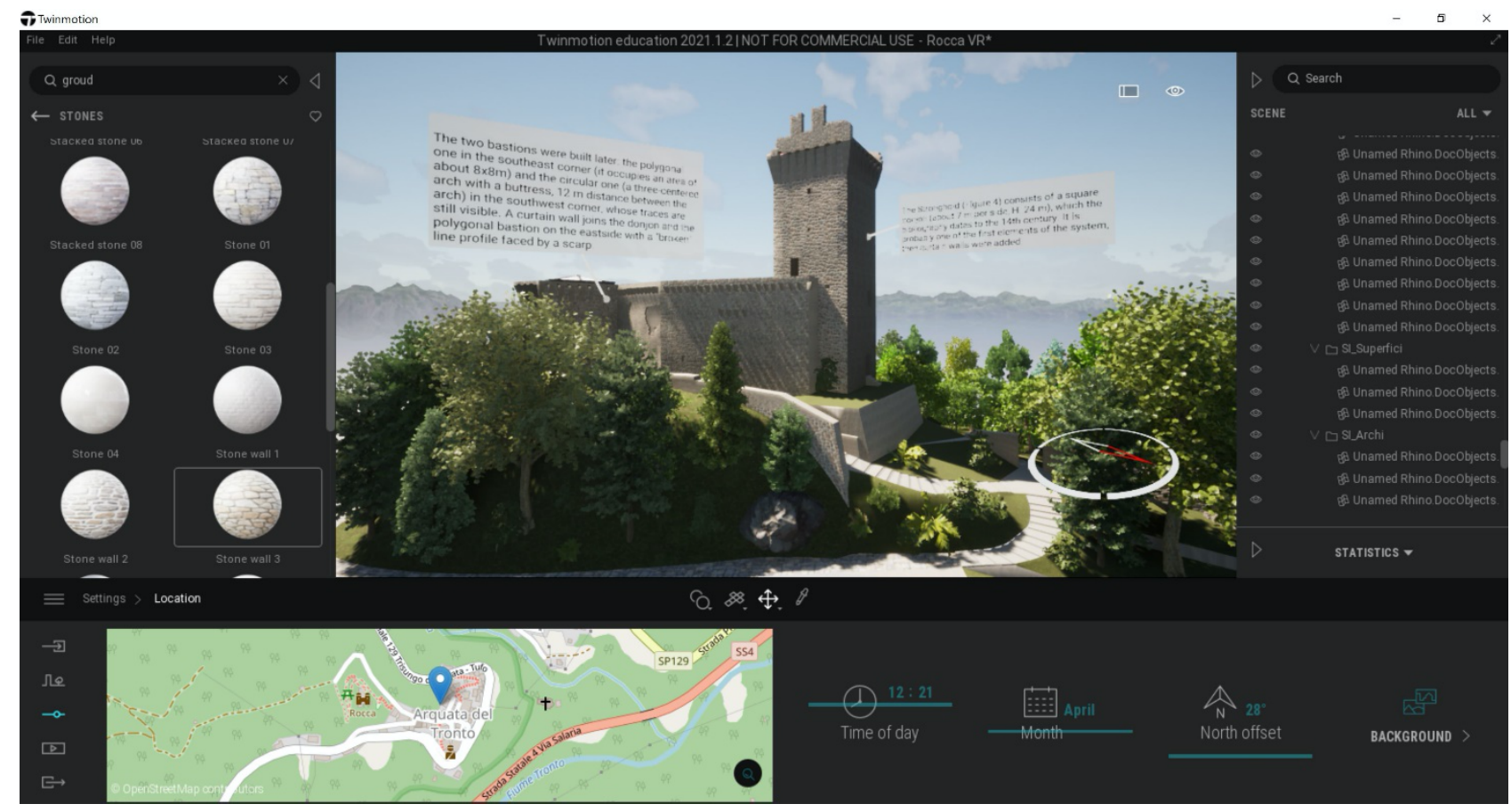

Figure 11. The VR project developed for the research case study. 


\section{CONCLUSIONS AND FUTURE PERSPECTIVES}

The quality of the modelling does not depend exclusively on the grade of accuracy that generates the object in three dimensions. It depends instead on responding to a need. While some parts of the Stronghold were built with less detailed model scales, the eastern curtain wall stratigraphy was deepened to understand possible causes of decay and possible interventions.

Not surprisingly, the part that most suffered the effect of the earthquake (near the polygonal bastion) are the ones that had been already repaired at the beginning of the $20^{\text {th }}$ century. Thus, it is important to understand the possible causes to avoid further damages.

The interoperability between different software made it possible to share data with the subjects involved in the project (restorers, structural engineers, ...) and oriented the model towards virtual reality for storytelling of the Stronghold, raising awareness of the importance of the monument within a landscape that, after the earthquake, should restart from new centralities.

On the one hand, the following studies will be oriented to deepen some aspects of the eastern curtain wall and face restoration operations. On the other hand, the same method will also be applied to other parts of the Stronghold to deepen its study and knowledge.

\section{ACKNOWLEDGEMENTS}

The authors thank the Municipality of Arquata del Tronto (RUP Mauro Fiori and arch. Davide Olivieri).

EU Study VIGIE 2020/654 funded tender on Study on quality in $3 \mathrm{D}$ digitisation of tangible cultural heritage, coordinator CUT Cyprus, ERA CHAIR and UNESCO CHAIR.

\section{CREDITS}

Surveying and scan-to-BIM process, Scientific responsible: Brumana R. Laser scanning responsible: M. Previtali, F. Roncoroni. 2D drawings, HBIM and XR projects: F. Banfi, C. Stanga (POLIMI DABC, Lab. GIcarus).

Preliminary Restoration Design, Scientific Responsible Manager: A. Grimoldi and A. G. Landi. Collaborators: E. Facchi, E. Zamperini (POLIMI DAStU).

\section{REFERENCES}

Banfi, F., 2020. HBIM, 3D drawing and virtual reality for archaeological sites and ancient ruins. Virtual Archaeology Review, 11(23), 16-33. https://doi.org/10.4995/var.2020.12416

Brogiolo, G. P., Cagnana, A., 2012. Archeologia dell'architettura. Metodi e interpretazioni. All'Insegna del Giglio, Firenze.

Brumana, R., Stanga, C., Banfi, F., 2021. Models and scales for quality control: toward the definition of specifications (GOALOG) for the generation and re-use of HBIM object libraries in a Common Data Environment. Applied geomatics. https://doi.org/10.1007/s12518-020-00351-2

Campagnoli, G., 1985. Architettura fortificata nelle Marche: mura, torri, rocche, castelli. Silvana editoriale, Milano.

Chiabrando, F., Lo Turco, M., Rinaudo, F., 2017. Modeling the decay in an HBIM starting from 3D point clouds. A followed approach for cultural heritage knowledge. International Archives of the Photogrammetry, Remote Sensing \& Spatial Information
Sciences, 42(2W5), 605-612. https://doi.org/10.5194/isprsarchives-XLII-2-W5-605-2017

Facchi, E., Grimoldi, A., Landi A. G., Zamperini, E., 2020. Reconstructed overhanging battlements. Executive techniques and their vulnerability in the stronghold of Arquata del Tronto (Italy). Roca. P., Pelà, L., Molins, C. (eds), Proceedings of the $12^{\text {th }}$ International Conference on Structural Analysis of Historical Constructions SAHC 2020 (forthcoming)

Doglioni, F., 1997. Stratigrafia e restauro. Tra conoscenza e conservazione dell'architettura. Edizioni Lint, Trieste.

Jang, J., Ko, Y., Shin, W. S., Han, I., 2021. Augmented Reality and Virtual Reality for Learning: An Examination Using an Extended Technology Acceptance Model. IEEE Access, 9, 6798-6809. https://doi.org/10.1109/ACCESS.2020.3048708

Petrucci, E., Lapucci, D., Lapucci, N., 2020. La Rocca di Arquata del Tronto: simbolo di rinascita per il territorio marchigiano colpito dal sisma. Navarro Palazón, García-Pulido (eds), Defensive Architecture of the Mediterranean, vol. XII, 13351342. https://dx.doi.org/10.4995/FORTMED2020.2020.11371

Quattrini, R., Pierdicca, R., Morbidoni C., 2017. Knowledgebased data enrichment for HBIM: exploring high- quality models using the semantic-web. Journal of Cultural Heritage, 28, 129139. https://doi.org/10.1016/j.culher.2017.05.004 